San Jose State University

SJSU ScholarWorks

Faculty Publications

Physics and Astronomy

January 2012

\title{
Elements of Proximal Formative Assessment in Learners' Discourse about Energy
}

\author{
Benedikt W. Harrer \\ University of Maine - Main, benedikt.harrer@sjsu.edu \\ Rachel E. Scherr \\ Seattle Pacific University \\ Michael C. Wittmann \\ University of Maine - Main \\ Hunter G. Close \\ Texas State University - San Marcos \\ Brian W. Frank \\ Middle Tennessee State University
}

Follow this and additional works at: https://scholarworks.sjsu.edu/physics_astron_pub

Part of the Physics Commons, and the Science and Mathematics Education Commons

\section{Recommended Citation}

Benedikt W. Harrer, Rachel E. Scherr, Michael C. Wittmann, Hunter G. Close, and Brian W. Frank. "Elements of Proximal Formative Assessment in Learners' Discourse about Energy" AIP Conference Proceedings (2012): 203-206.

This Article is brought to you for free and open access by the Physics and Astronomy at SJSU ScholarWorks. It has been accepted for inclusion in Faculty Publications by an authorized administrator of SJSU ScholarWorks. For more information, please contact scholarworks@sjsu.edu. 


\title{
Elements of Proximal Formative Assessment in Learners' Discourse about Energy
}

\author{
Benedikt W. Harrer*, Rachel E. Scherr ${ }^{\dagger}$, Michael C. Wittmann*, Hunter G. Close** \\ and Brian W. Frank \\ ${ }^{*}$ Department of Physics and Astronomy, University of Maine, Orono, ME 04469 \\ ${ }^{\dagger}$ Department of Physics, Seattle Pacific University, Seattle, WA 98119 \\ ${ }^{* *}$ Department of Physics, Texas State University, San Marcos, TX 78666 \\ ${ }^{\ddagger}$ Department of Physics and Astronomy, Middle Tennessee State University, Murfreesboro, TN 37132
}

\begin{abstract}
Proximal formative assessment, the just-in-time elicitation of students' ideas that informs ongoing instruction, is usually associated with the instructor in a formal classroom setting. However, the elicitation, assessment, and subsequent instruction that characterize proximal formative assessment are also seen in discourse among peers. We present a case in which secondary teachers in a professional development course at SPU are discussing energy flow in refrigerators. In this episode, a peer is invited to share her thinking (elicitation). Her idea that refrigerators move heat from a relatively cold compartment to a hotter environment is inappropriately judged as incorrect (assessment). The "instruction" (peer explanation) that follows is based on the second law of thermodynamics, and acts as corrective rather than collaborative.
\end{abstract}

Keywords: proximal formative assessment, energy, professional development, discourse PACS: 01.40.Fk, 01.40.jh, 01.40.E-

\section{INTRODUCTION}

Formative assessment is the process of assessing students' learning in order to inform ongoing instruction that is supposed to help the students reach their learning goals. In comparison to formal classroom assessment activities (quizzes, tests, homework, etc.) which can inform instruction on a day-to-day basis, proximal formative assessment [1] refers to informal [2], interactionembedded [3] practices of formative assessment that help the teacher to productively structure the learning environment in the moment.

The term proximal formative assessment was introduced by Erickson [1] to mean any actions a teacher might take in order to find "locally available evidence of student learning." These actions lead to the just-in-time elicitation of a student's idea, the evaluation and assessment of this idea, and an immediate response (e.g. an instructional piece) that helps the student further develop her understanding.

In this paper, we argue that elements of proximal formative assessment can also be seen in discourse among teachers in a professional development environment. Tapping into these already existing resources could be of value for future implementations of teacher professional development concerning proximal formative assessment.

We take a closer look at the case of three secondary teachers (pseudonyms Donna, Mark and Victoria) during an initial discussion about energy dynamics in a refrigerator. The teachers worked together in a group during a summer professional development course at Seattle Pacific University. The course was offered as part of the Energy Project, a professional development and physics education research program for the teaching and learning of energy [4].

\section{DATA AND METHODOLOGY}

The three teachers in our episode had already spent much time thinking about energy in simple situations like a hand pushing a box across a floor or an oscillating cart on a spring.

At the beginning of the instructional session surrounding the episode, the instructors introduce a new, more complex scenario. The teachers are supposed to find out about the energy dynamics in a refrigerator, starting out with what they already know about refrigerators from everyday experience.

In order to understand learners' ideas and arguments in group settings, we benefit from attending not only to the words spoken, but also to other communicative channels like prosody (rhythm and tone of speech) and gestures. $[5,6]$

We use a microethnographic approach to analyze Donna's, Mark's and Victoria's talk and bodily action [7], with video recordings as our primary data sources [8]. In a detailed moment-by-moment analysis of a 1.5min episode of their video-recorded interaction, we will identify the teachers' ideas, show evidence for their com- 
mitments to these ideas, and show how this interaction contains elements of proximal formative assessment.

\section{ELEMENTS OF PROXIMAL FORMATIVE ASSESSMENT}

\section{Elicitation: "What are you thinking?"}

Donna and Mark had started thinking about the energy dynamics in a refrigerator from the inside. Donna had pointed out that there are coils on the inside of the refrigerator, and another set of (hot) coils in the back.

In the minutes before our episode, Mark had explained that there is a liquid inside the coils that circulates through them. According to Mark, thermal energy flows from the contents of the inside compartment of the refrigerator into the liquid in the coils. The liquid moves to the back of the refrigerator where the heat flows from the liquid into the environment. Mark's physically accurate explanation of the mechanism for this is that the inside of the refrigerator has to be at a higher temperature than the liquid, whereas the liquid has to be hotter than the environment. The thermal energy "always has to go from hot to cold." Donna had agreed to this statement of Mark's.

Their conversation lasts several minutes, during which Victoria is silent. When Donna and Mark seem to reach a "dead end" in their discussion, Donna tries to directly elicit Victoria's thinking by inviting her to share her ideas with the group: "Victoria, what are you thinking?" (Table 1, line 1)

Victoria responds that she doesn't think her answer is meaningful, but that in her opinion, the energy flows from cold to hot (line 2). In the further discourse between the three teachers (lines 3-11), Victoria elaborates on her idea. From the transcript, we can infer that she thinks thermal energy flows from cold to hot in a refrigerator. The heat flow from cold to hot is not a spontaneous process. Electrical energy has to be spent in order to make it happen (line 8).

\section{Assessment: "Wait..."}

Although Victoria starts to explain her idea during her first statement (line 2), Mark cuts her off and says "Wait..." maybe realizing that her idea is different from his and Donna's.

This realization seems similar to the result of an assessment: The student's idea was compared to the teacher's idea, the classroom standard or learning goal. Mark's assessment of Victoria's idea seems to be completed after line 3: He does not elicit or acknowledge further explanations. Our microanalysis of Victoria's utter-
TABLE 1. Verbal transcript of the video episode

\begin{tabular}{|c|c|c|}
\hline 1 & Donna: & $\begin{array}{l}\text { Does that... Victoria, what are you think- } \\
\text { ing? }\end{array}$ \\
\hline 2 & Victoria: & $\begin{array}{l}\text { Umm... I am thinking that I don't have } \\
\text { a meaningful answer. So, I know the en- } \\
\text { ergy flows from the cold to the hot. And } \\
\text { this happened just because... }\end{array}$ \\
\hline 3 & Mark: & Wait... \\
\hline 4 & Victoria: & Yeah \\
\hline 5 & Mark: & $\begin{array}{l}\text { No, (Donna: No) energy always goes } \\
\text { from hot to cold (Donna together with } \\
\text { Mark: ...to cold). }\end{array}$ \\
\hline 6 & Victoria: & $\begin{array}{l}\text { There is... Inside of the refrigerator, it's } \\
\text { colder than outside. }\end{array}$ \\
\hline 7 & Mark: & Yes. \\
\hline 8 & Victoria: & $\begin{array}{l}\text { So, somehow, you spend energy, right? } \\
\text { The electrical energy, to make, uhm, ther- } \\
\text { mal energy to go from the cold to the hot. }\end{array}$ \\
\hline 9 & Victoria: & $\begin{array}{l}\text { Which apparently doesn't make any } \\
\text { sense, but this, if I would ask my stu- } \\
\text { dents, this is what they are going to... to } \\
\text { know. }\end{array}$ \\
\hline 10 & Mark: & Yeah, I mean I think... \\
\hline 11 & Victoria: & $\begin{array}{l}\text { If it's really warm outside, then you'll } \\
\text { hear the refrigerator just working hard } \\
\text { to make the inside much colder than the } \\
\text { outside. }\end{array}$ \\
\hline 12 & Mark: & Right. \\
\hline 13 & Donna: & Yeah. \\
\hline 14 & Victoria: & OK. \\
\hline 15 & Donna: & $\begin{array}{l}\text { But it's not because energy flows from } \\
\text { cold to hot (Victoria: No, no.). It's be- } \\
\text { cause it's hot to cold. }\end{array}$ \\
\hline 16 & Victoria: & But... \\
\hline
\end{tabular}

ances in a later section will show that her idea is correct and appropriate.

However, Mark and Donna, who had previously established their commitment to the idea that thermal energy always goes from hot to cold (see above), react negatively to Victoria's statement: they shake their heads in unison and repeatedly say "no." These actions, as well as their definitive and complacent intonation of their idea about the direction of heat flow, ${ }^{1}$ give evidence of their assessment of Victoria's idea.

\footnotetext{
1 The pitch contour of Mark's statement can be categorized into the "Low Drop" tone group in the system of O'Connor and Arnold [9]. Statements associated with this tone group generally sound definite and complete. Since Mark emphasizes the first syllable of the word "energy," his statement contains a "head," which suggests that it carries strength and power. According to O'Connor and Arnold, "This power may lend itself to utterances of a categoric, weighty, judicial, considered kind." [9] pg. 48; emphases in the original.
} 


\section{Response: "No, energy always goes from hot to cold."}

After hearing Victoria's initial statement of her idea and comparing it to their own, Donna and Mark shake their heads in disagreement and Mark states that "energy always goes from hot to cold," which is repeated by Donna later on. Mark and Donna's statement has much scientific merit and is in that sense a valuable instructional response.

According to the second law of thermodynamics, thermal energy can only spontaneously flow in one direction, from an object at relatively higher temperature to an object at relatively lower temperature. Although Donna and Mark do not explicitly mention spontaneous heat flow, their notion of heat flowing from warmer to colder objects without any kind of agent seems to imply spontaneity. In any case, they are correct in referring to this law when they talk about the heat transfer from the relatively colder compartment inside a refrigerator to the refrigerant, and from the refrigerant into the relatively hotter environment.

Also, it is a valid approach to the thinking about energy dynamics in refrigerators, to start out considering the actual physical parts of the refrigerator that one can see/feel: The coils inside a refrigerator take up heat from a finger if touched, the moisture on the skin freezes, the finger is "stuck" to the coils. Similarly, the skin of the finger gets warm if the coils in the back of the refrigerator are touched, since heat is transferred from the refrigerant to the finger.

\section{Making more meaning of Victoria's answer}

As mentioned above, Donna and Mark do not elicit further elaborations on Victoria's idea, and they do not acknowledge her repeated attempts to explain herself. However, although Victoria said that she didn't have a meaningful answer (line 2), we were already able to identify her idea of energy going from cold to hot in a refrigerator. In this section, we analyze gestures and prosody to provide additional meaning to her response.

In addition to her verbal utterances, Victoria's gestures also illustrate her idea. When she says "make the inside," (line 11) Victoria uses her left hand to perform a repeated grasping gesture in front of her. The words "much colder than the outside" (line 11) are accompanied by releasing gestures to the right of her body that looks like she is dropping something or throwing it away. It seems like the grasping gesture illustrates taking out thermal energy from the colder inside (which is located in front of her) and the releasing gesture shows giving off the picked up thermal energy into the warmer outside (which is located to the right front of her body).

Victoria's gestures seem to communicate her thinking about the mechanism by which the inside of the refrigerator is being made "much colder than the outside." This supports her idea that something has to do work to move thermal energy from the cold (inside) to the hot (outside).

This idea is valid. Macroscopically speaking, thermal energy flows from cold to hot in a refrigerator; that is the unique thermodynamic property of the device. The heat flow from cold to hot is not a spontaneous process. Something - in household refrigerators, an electric motor - has to do work in order to make it happen. [10]

The intonation of her statement, "I know the energy flows from the cold to the hot" (line 2) suggests that she strongly believes in her idea. The word "know" is prolonged, and the intonation contour resembles the pattern "rise-fall-rise" (Fig. 1), similar to somebody saying "duh" (Fig. 2). [11]

The length of the word draws attention to it. It seems to be the most important word in the sentence. Also, the complex pitch contour suggests importance and stress of this word. This, combined with the fact that the intonation is so similar to the typical pitch contour of the word "duh," suggests that Victoria believes that she really knows that the "energy flows from the cold to the hot," and that this statement is so obvious that Donna and Mark would be foolish not to believe it.

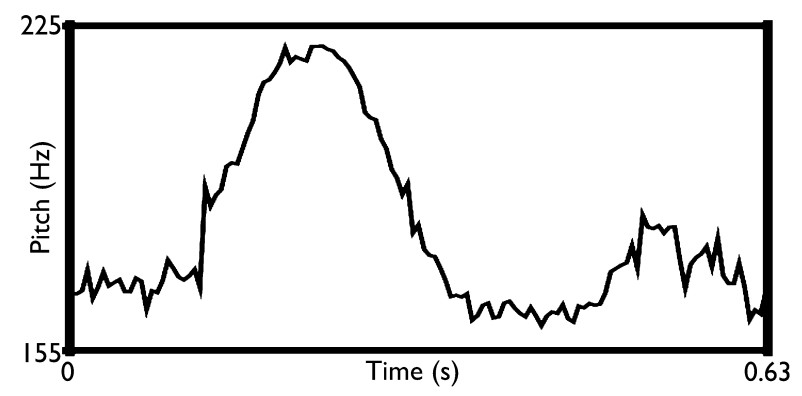

FIGURE 1. Intonation contour of Victoria's utterance of "know." Graph created using [12]

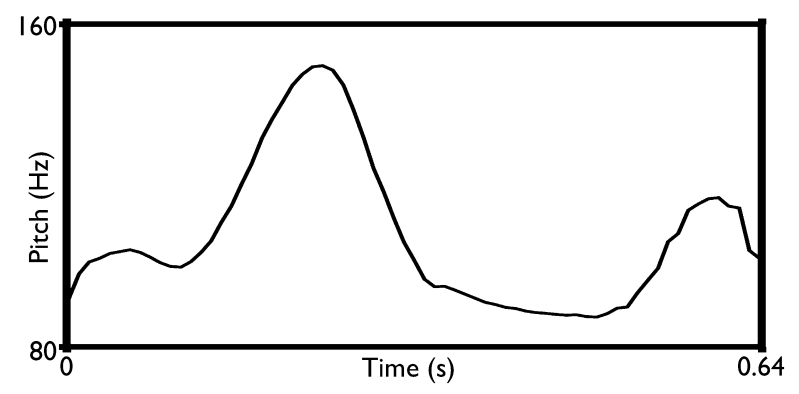

FIGURE 2. Intonation contour of "duh." Audio sample downloaded from merriam-webster.com, graph created using [12] 
Had Mark and Donna attended to all modes of the ongoing communication, they might have been better able to recognize the quality of Victoria's statement, and react accordingly. Victoria's idea is physically accurate. Further elicitation of the reasons behind her commitment might have helped Donna and Mark to better understand her idea and see the value in it.

\section{CONCLUSION}

We have found elements of proximal formative assessment in the discourse among three teachers in a professional development environment. The three steps, elicitation of ideas, assessment, and response are not only carried out by instructors in formal classroom environments, but also in the peer discourse of teachers.

Our analysis of the video recording of Donna, Mark, and Victoria has illustrated how the hasty and maybe inappropriate judgment of an idea can lead to a rather corrective attempt of teaching a different idea.

Using multimodal analysis we were able to reconstruct a more complex picture of Victoria's thinking than Donna and Mark were able to. We paid attention not only to Victoria's verbal utterances (transcript), but also her gestures and her prosody. She firmly believes in her idea that something has to take out thermal energy from the colder compartment and release it into the hotter environment, and therefore energy flows from cold to hot in a refrigerator.

Both ideas are completely valid and appropriate. Reconciling the microscopic and macroscopic view of energy flow is a crucial step in understanding how refrigerators work. Since a collaborative effort to construct understanding was prevented, a learning opportunity was missed.

We think that it is an important part of proximal formative assessment to attend to all modes of communication and reserve judgment on a learner's idea until the idea is well understood and its strengths and weaknesses are known. We suggest that exploration of a learner's commitment to an idea can be a valuable source of information. It may have the benefit of allowing for better evaluation of the learner's idea and helping to find a more appropriate response.

\section{ACKNOWLEDGMENTS}

We are grateful to the participants and instructors of the Energy Project summer professional development courses 2010 at SPU for letting us in on their thinking. We would also like to thank Virginia Flood and Adam Kaczynski (both University of Maine) for helpful and productive discussions during the analysis.

\section{REFERENCES}

1. F. Erickson, "Some Thoughts on "Proximal" Formative Assessment of Student Learning," in Evidence and Decision Making, edited by P. Moss, Blackwell Publishing, Malden, MA, 2007, vol. 106 of National Society for the Study of Education yearbook, pp. 186-216.

2. M. A. Ruiz-Primo, and E. M. Furtak, Journal of Research in Science Teaching 44, 57-84 (2007).

3. R. P. Durán, Review of Research in Education 32, 292-327 (2008).

4. H. G. Close, L. S. DeWater, E. W. Close, R. E. Scherr, and S. B. McKagan, "Using the Algebra Project Method to Regiment Discourse in an Energy Course for Teachers," in Physics Education Research Conference 2010, edited by C. Singh, M. Sabella, and S. Rebello, 2010, vol. 1289 of AIP Conference Proceedings, pp. 9-12.

5. E. W. Close, H. G. Close, S. B. McKagan, and R. E. Scherr, "Energy in Action: The Construction of Physics Ideas in Multiple Modes," in Physics Education Research Conference 2010, edited by C. Singh, M. Sabella, and S. Rebello, 2010, vol. 1289 of AIP Conference Proceedings, pp. 105-108.

6. R. E. Scherr, Phys. Rev. ST Phys. Educ. Res. 4, 010101 (2008).

7. J. Streeck, and S. Mehus, "Microethnography: The Study of Practices," in Handbook of Language and Social Interaction, edited by K. L. Fitch, and R. E. Sanders, Lawrence Erlbaum Associates, Inc., 2005, chap. 15, pp. 381-404.

8. B. Jordan, and A. Henderson, The Journal of the Learning Sciences 4, 39-103 (1995).

9. J. D. O'Connor, and G. F. Arnold, Intonation of Colloquial English, Longman Group Ltd., London, 1973, 2nd edn.

10. D. V. Schroeder, Introduction to Thermal Physics, Addison Wesley Longman, San Francisco, California, 2000.

11. N. Constant, English rise-fall-rise: A study in the semantics and pragmatics of intonation (2006), URL http://www.yikes.com/ noah/thesis/ Constant_RFR.pdf, unpublished Masters Thesis.

12. P. Boersma, and D. Weenink, Praat: doing phonetics by computer [computer program] (2011), URL http://www.praat.org/, version 5.2.25. 
Copyright of AIP Conference Proceedings is the property of American Institute of Physics and its content may not be copied or emailed to multiple sites or posted to a listserv without the copyright holder's express written permission. However, users may print, download, or email articles for individual use. 